\title{
Biofilm Detection and Clinical Significance of Staphylococcus epidermidis Isolates in a Tertiary Care Hospital, Karimnagar, India
}

\author{
Kondal Rao Ravilla ${ }^{1}$, Amar C. Sajjan ${ }^{1 *}$ and Sachin Gurnule ${ }^{2}$ \\ ${ }^{1}$ Department of Microbiology, ${ }^{2}$ Department of Community Medicine, \\ CAIMS Karimnagar, India
}

\section{A B S T R A C T}

\section{Keywords}

Coagulase negative Staphylococci, Biofilm,

Staphylococcus epidermidis

Article Info

Accepted:

15 November 2018

Available Online:

10 December 2018
Aims of the study are to detect biofilm producing Staphylococcus epidermidis isolated from various clinical specimens. Total 73 Staphylococcus epidermidis isolates were collected from clinical samples like blood, post-operative wound swabs, IV catheter tips, catheterized urine, and exudates received from various clinical departments. The study was carried out over a period of one year. The specimens received were processed by conventional methods. Tissue Culture plate method was used for detection of biofilm. IV catheter tip samples revealed $25 \%$, implant device associated infections revealed $20 \%$, the Catheterized urine samples showed $17 \%$, blood culture $6 \%$, ventilator associated infections $20 \%$, post-operative wound infections $13.29 \%$ and exudates $3.33 \%$ of Staphylococcus epidermidis isolates. Isolates with $\mathrm{O}$. D. values more than 0.2 were considered as high biofilm producers. $52.1 \%$ of $S$. epidermidis isolates were weak biofilm producers, $24.66 \%$ were moderate biofilm producers and $20.54 \%$ were high biofilm producers. Isolates from IV catheter tips showed high biofilm formation. Increase in use of implant devices, unnecessary and prolonged use of urinary catheter and IV catheters can lead to biofilm formation which pose difficulty in treating and eradicating them.

\section{Introduction}

Once coagulase-negative staphylococci like $S$. epidermidis was considered as just a commensals of human skin and mucus membrane, but now accepted as important opportunistic pathogen especially in hospital setup (Post et al., 2017). The CONS have the ability to switch from commensals to pathogen. This is facilitated by its rapid attachment and forming biofilm on medical devices. S. epidermidis accounts upto $43 \%$ of cases of orthopedic device related infection and (Post et al., 2017; Kloos et al., 1994). animals. The initial stage of biofilm formation has important role in S. epidermidis abiotic surface colonization (Macro). (Artini et al., 2017; Jeong et al., 2006; Spencer et al., 1996) Their role as significant pathogens following ophthalmologic, neurologic or cardiothoracic surgery, in immune compromised patients and in the patients with prosthetic devices has been established. Besides this we can see now that the infections of CONS are generally associated with the use of catheter and other medical devices. It has been implicated as the etiological agent in infections of wound, urogenital tract, respiratory tract, meninges, 
conjunctiva and skin. This three-dimensional biofilm structure is made up in $85 \%$ cases by the extracellular matrix which comprises polysaccharides, proteins, enzymes, DNA, bacterial glycolipids, water, and in $15 \%$ cases by aggregates of microorganism cells. (Costerton et al., 1999; Hidron et al., 2008) Biofilm development depends on many physical, chemical and biological factors (Rupp and Archer, 1994). It is a partially deacylated polymer of $\beta-1, \quad 6-\mathrm{N}$ acetylglucosamine, which, with the other polymers such as teichoic acids and proteins, can form a major part of the extracellular matrix. Recently, PIA homologues were identified in many pathogens with biofilm formation ability, which points out towards the assumption that three-dimensional matrix formation plays a crucial role in bacterial virulence in (biofilm-associated infections) (Wang et al., 2004; Kalpana, 2004; Darby et al., 2002).

PIA biosynthesis is carried out by the proteins encoded by the ica gene operon: $\mathrm{N}$ acetylglucosamine transferase (icaA and icaD), PIA deacylase (icaB), PIA exporter (icaC) and the regulatory gene (icaR) Vuong C 2004Gerke C 1998) Ica locus expression is regulated by a variety of environmental factors and internal regulatory proteins. Biosynthesis and deacetylation of PIA are recognized as crucial virulence factors in Staphylococcus epidermidis-associated infections (Rupp et al., 2001; Singh and Banerjee, 2008; Fluckiger et al., 2005).

As so many cases of resistance organism are trending in recent times and considering the increasing use of medical devices, this study was conducted in tertiary care hospital to detect biofilm producing S. epidermidis

\section{Materials and Methods}

73 Staphylococcal epidermidis isolates were collected from clinical samples like wound swabs, blood, IV catheter tips, catheterized urine, and exudates received from various clinical specimens. Biofilm formation was studied in these isolates. The study was carried out over a period of one year i. e. from September 2017- September 2018. The specimens received were processed by conventional methods. $15 \mathrm{cfu}$ from IV catheter tips were given significance.

\section{Processing of the specimens}

Isolates were identified by standard microbiological procedures like Gram staining, colonial morphology, slide and tube coagulase test, biochemical tests.

\section{Detection of biofilm production}

Tissue Culture plate method is used for detection of biofilm.

\section{Identification of Staphylococcus epidermidis}

Colonies from blood agar plates were picked up and Gram stained. Catalase and coagulase tests were done. All CONS are tested for Novobiocin sensitivity. Sensitive strains were identified as Staphylococcus epidermidis. Staphylococcus epidermidis isolates where preserved in $20 \%$ glycerol broth. Isolates of Staphylococcus epidermidis were screened for their ability to form biofilm by Tissue culture plate method.

\section{Procedure}

Clinical isolates from fresh agar plates were inoculated in BHI (Brain heart infusion broth) with $2 \%$ sucrose and incubated for $18 \mathrm{hrs}$ at $37^{\circ} \mathrm{C}$ in stationary condition. The cultured broth was diluted 1 in 100 with fresh medium. Sterile ELISA plate was taken and filled with $0.2 \mathrm{ml}$ of the diluted cultures. The ELISA plate was incubated for $24 \mathrm{hrs}$ at $37 \mathrm{C}$. After incubation, contents of each well were gently removed. The wells were washed 4 times with 
$0.2 \mathrm{ml}$ of phosphate buffer saline to remove the free floating bacteria. Biofilms formed by adherent organisms in plate were fixed with $2 \%$ sodium acetate and stained with $0.1 \%$ Crystal Violet. Excess stain was rinsed off by thorough washing with deionized water, plates were kept for drying. Adherent Staphylococcal cells usually formed biofilms on all side walls and were uniformly stained with Crystal Violet. Optical density of stained adherent bacteria was determined using micro ELISA auto reader at wavelength between 400-600 nm. These OD values were considered as an index of bacteria adhering to surface and forming biofilms.

\section{Results and Discussion}

A total of 73 Staphylococcus epidermidis isolates from 690 culture positive samples. IV catheter tip samples revealed $25 \%$ which is higher than other specimen like implant device associated infections revealed 20\%, the Catheterized urine samples showed $17 \%$, blood culture $6 \%$, ventilator associated infections 20\%, post-operative wound infections $13.29 \%$ and exudates $3.33 \%$ of Staphylococcus epidermidis isolates which found highly statistical significant at $1 \%$ (Table 1). Isolates with $\mathrm{O}$. D. values more than 0.2 were $40 \%$ of $S$. epidermidis isolates were weak biofilm producers, $24 \%$ were moderate biofilm producers and $36 \%$ were high biofilm producers (Table 2).

Isolates with $\mathrm{O}$. $\mathrm{D}$. values more than 0.2 were considered as high biofilm producers. Isolates from IV catheter tips showed high biofilm formation. (Table 3 and Fig. 1).

Table shows that, among the various specimens, IV catheter tip showing higher biofilm producing organism followed by Catheterized urine specimen.

Earlier, Coagulase negative staphylococci (CONS) were considered as harmless skin commensals and dismissed as culture contaminants. But in recent years they are increasingly being recognized as important human pathogens. Among all CONS, $S$. epidermidis strains represent the most frequent cause of nosocomial sepsis and the most common agents of infections with implanted devices.

Table.1 Staphylococcus epidermidis isolates from various clinical specimen

\begin{tabular}{|l|c|c|c|c|}
\hline Nature of Specimen & No of Samples & $\begin{array}{c}\text { Number of } \\
\text { S. epidermidis }\end{array}$ & $\begin{array}{c}\text { Percentage of } \\
\text { S. epidermidis }\end{array}$ & P-Value \\
\hline Post-operative & 173 & 23 & 13.29 & \\
\hline wound infections & 32 & 8 & 25 & \\
\hline IV catheter tips & 10 & 2 & 20 & \multirow{2}{*}{$0.0003^{* *}$} \\
\hline Ventilator associated & 15 & 3 & 20 & \\
\hline infections & & & & \\
\hline Implant Device & 100 & 17 & 17 & \\
\hline associated infections & 60 & 2 & 3.33 & \\
\hline Catheterized Urine & 300 & 18 & 6 & \\
\hline Exudates & & & & \\
\hline Blood Culture & & & & \\
\hline
\end{tabular}


Table.2 O. D. values of biofilm producing S. epidermidis Nature of specimen

\begin{tabular}{|c|c|c|}
\hline & No. of S. epidermidis & \% of S. epidermidis \\
\hline Mean O. D. values & isolates & Isolates \\
\hline$<\mathbf{0 . 1}$ & 20 & 40 \\
\hline $\mathbf{0 . 1 - 0 . 2}$ & 12 & 24 \\
\hline$>\mathbf{0 . 2}$ & 18 & 36 \\
\hline \hline
\end{tabular}

Table.3 O.D. Values of biofilms formed by S. epidermidis strain from different clinical samples

\begin{tabular}{|c|c|c|c|c|}
\hline \multirow[t]{2}{*}{ Nature of specimen } & \multirow[b]{2}{*}{$>0.2$} & \multirow{2}{*}{$\begin{array}{r}\text { OD } \\
\text { Values } \\
\mathbf{0 . 1 - 0 . 2}\end{array}$} & \multirow[b]{2}{*}{$<0.1$} & \multirow[t]{2}{*}{$\mathrm{p}$-Value } \\
\hline & & & & \\
\hline IV catheter tips & 8 & 1 & 1 & \\
\hline Implant device associated & 2 & 0 & 0 & \\
\hline Catheterized urine & 4 & 4 & 2 & \\
\hline Blood cultures & 3 & 2 & 3 & $0.007 * *$ \\
\hline \multicolumn{5}{|l|}{ Ventilator associated } \\
\hline infection & 1 & 1 & 0 & \\
\hline Exudates & 0 & 1 & 1 & \\
\hline Post-operative wound swabs & 2 & 6 & 8 & \\
\hline
\end{tabular}

Figure.1 O. D. values of biofilm producing S. epidermidis

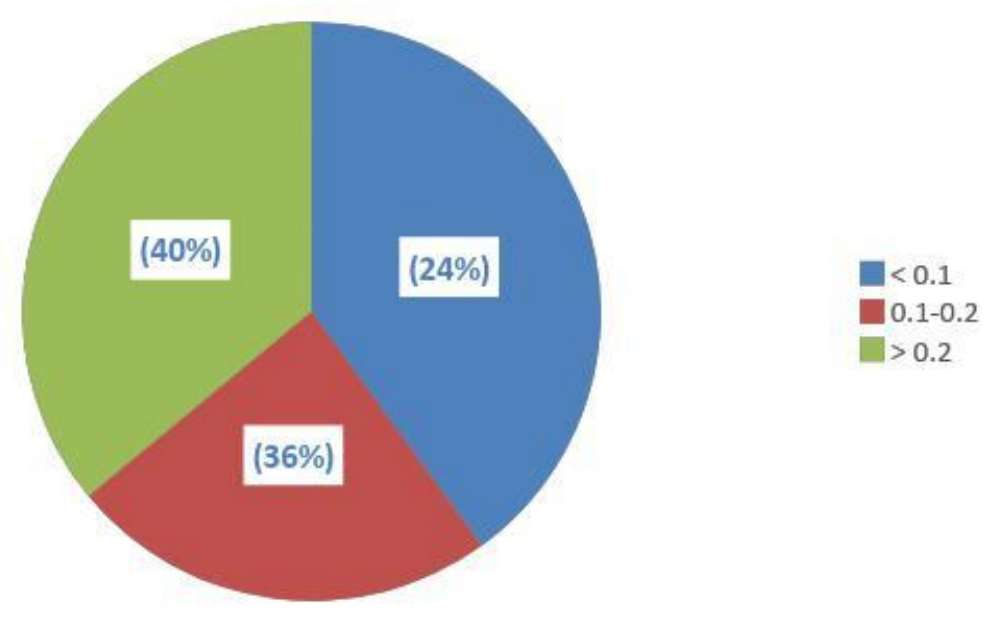


In a study done by Shubhra Singh, Gopa Banerjee et al., showed 72 among 150 strains of CONS $(60 \%)$ were isolated from blood samples, 36 from pus samples, 15 from (Sing S 2008) urinary catheter tip and 12 from the urine samples. In another study done by Azuka Azih and Idahosa Enabulele et al., CONS were most commonly isolated from infected wounds $(17.7 \%)$, followed by urine from cases of urinary tract infections.(16.5\%) and least isolated from ear infections (1.26\%). Infected wounds were mainly from surgical wounds, diabetic foot ulcer and prosthetic devices. (Azuka Azih et al., 2013)

Previously, many workers have demonstrated biofilm formation by $S$. epidermidis from clinical isolates. Biofilm was detected mainly from the strains isolated from device associated infection followed by IV catheter associated septicaemias. S. epidermidis is an opportunistic pathogen of foreign bodies' particularly prosthetic cardiac valves, CSF shunts, orthopedic appliances and other devices. In a study done by Rohde $\mathrm{H}$, Burdelskic et al., 2005, showed that because of its biofilm forming capacity $S$. epidermidis has evolved as a leading cause of device related infections. (Rohde H 2005)

In the present study we found that $S$. epidermidis forms biofilms.

The findings correlate well with the others mentioned above. In another study S. Mathur et al., 2006 evaluated three methods for detection of biofilm formation in $S$. epidermidis by tissue culture plate (TCP) method, Tube method and Congo red agar (CRA) method. Of these they found the TCP method was the most sensitive and accurate method for detection of bio film formation (Mathur, 2006). In another study done by Afreenish Hassan, Javaid Usman et al., the TCP method was considered to be superior to TM and CRA. From the total of 110 clinical isolates, TCP method detected $22.7 \%$ as high,
$41 \%$ moderate and $36.3 \%$ as weak or nonbiofilm producers (Afreenish Hassan et al., 2011).

In this study biofilm formation by tissue culture plate method because it was considered as standard test for detection of biofilm formation. In the present study, we screened all isolates of $S$. epidermidis from clinical samples from blood cultures, IV catheter tips, ventilator associated infections, implant device associated, catheterized urine, exudates and postoperative wound infections.

So concluded, in the modern health care setup, various devices such as IV catheters, urine catheters, shunts, implanted prosthetic devices, etc. are used increasingly thereby causing device associated infections particularly of Staphylococcus epidermidis. In the present study we have been able to demonstrate biofilm production by the clinical isolates of Staphylococcus epidermidis, mainly from device associated infections The optical density values were found to be more from IV catheter associated strains (>. 2, 8 isolates). Post-operative wound infections (stitch abscesses) revealed least optical density. Therefore it is concluded that the device associated infections caused by Staphylococcus epidermidis are mainly due to biofilm formation which ultimately makes treatment difficult.

\section{References}

Afreenish Usman et al. 2011. Evaluation of different detection. Hassan Javaid methods of biofilm formation in the clinical isolates. Brazilian jr of inf dis, 15: 305-311.

Azuka Azih and Idahosa Enabulele et al. 2013. Species Distribution and Virulence Factors of Coagulase Negative Staphylococci Isolated From Clinical Samples From the University of Benin Teaching Hospital, Edo State, 
Nigeria, Journal of Natural Sciences Research. 9(3):38-40.

Costerton, J. W., Stewart P. S., Greenberg, E. P.1999, Bacterial biofilms: A common cause of persistent infections. Science. 284: 1318-1322.

Darby, C., Hsu, J. W., Ghori, N., Falkow, S. 2002. Caenorhabditis. elegans: Plague bacteria biofilm blocks food intake. Nature. 16: 243- 244.

Fluckiger U., Ulrich M., Steiuhuber A., Döring G., Mack D., Landmann R., Goerke Ch., Wolz Ch. 2005. Biofilm formation, icaADBC transcription, and polysaccharide intercellular adhesin synthesis by staphylococci in a devicerelated infection model. Infect. Immun., 73: 1811-1819.

Hidron AI1, Edwards JR, Patel J. 2008 NHSN annual update: antimicrobial-resistant pathogens associated with healthcareassociated infections: annual summary of data reported to the National Healthcare Safety Network at the Centers for Disease Control and Prevention, 2006-2007. Infect Control Hosp Epidemiol.2008 Nov; 29(11): 996-1011.

Gerke, C. Kraft, A., Sussmuth, R., Schweitzer, O., Götz, F. 1998 Characterization of the Nacetylglucosaminyl transferase activity involved in the biosynthesis of the Staphylococcus epidermidis polysaccharide intercellular adhesion. J. Biol. Chem. 273: 18586-18593.

Izano, E., Amarante, M., Kher, W., Kaplan, J. 2008 Differential roles of poly-Nacetylglucosamine surface polysaccharide and extracellular DNA in Staphylococcus aureus and Staphylococcus epidermidis biofilms. Appl. Environ. Microbiol., 74: 470 476.

Jeong, I. S., Jeong, J. S., Choi, E. O. 2006. Nosocomial infection in a newborn intensive care unit (NICU), South Korea. BMC Infect. Dis. 23: 103-110.

Kaplana, J. B., Velliyagounder, K., Ragunath, Ch., Rode, H., Mack, D., Knobloch, J. K. 2004. Ramasbbu, NGenes involved in the synthesis and degradation of matrix polysaccharide in Actinobacillus. Actinomycetem comitans and Actinobacillus. pleuropneumoniae biofilms. J. Bacteriol. 186: 8213-8220.

Kloos, W. E., Bannerman, T. L. 1994. Update on clinical significance of coagulasenegative staphylococci. Clin. Microbiol. Rev. 7: 117-140.

Mathur, S. Singhal, 2006. Detection of Biofilm formation among the clinical isolates of Staphylococci: An evaluation of three different screening methods. IJMM. 24 (1); 25-9.

Marco artini, Paola Cicatiello, Annarita Ricciardelli, 2017. Hydrophobin coating prevents Staphylococcus epidermidis biofilm formation on different surfaces; 33(7): 601-611

Otto, M. 2009 Staphylococcus epidermidisthe "accidental" pathogen. Nat. Rev.Microbiol., 7: 555-567.

Post V. Harris LG, Morgenstern M, Mageiros L, Hitchings MD, Meric G, Pascoe B, Sheppard SK, Richars RG, Moriarty TF, 2017. Comparative Genomics Study of Staphylococcus epidermidis Isolates form Orthopedic-Device-Related Infections Correlated with Patient Outcome.55(10):3089-3103

Rohde H. Burdelskic. 2005. Induction of Staphylococcus epidermidis biofilm formation via proteolytic processing of the accumulation-associated protein by Staphylococcal and host proteases. Mol Microbiol; 55, (6): 1883-95.

Rupp, M. E., Archer, G. 1994. Coagulasenegative staphylococci: pathogens associated with medical progress. Clin. Infect. Dis. 19: 231-243.

Rupp, M. E., Fey, P. D., Heilmann, C., Götz, 
F. 2001. Characterization of the importance of Staphylococcus epidermidis autolysin and polysaccharide intercellular adhesin in the pathogenesis of intravascular catheter-associated infection in a rat model. J. Infect. Dis., 183: 10381042.

Singh S, Banerjee G. 2008. Simple method for speciation of clinically significant coagulase negative Staphylococci and its antibiotic sensitivity/resistant pattern in NICU of tertiary care centre. Biomedical Research. 19 (2): 97-101.

Spencer, R. C. 1996. Predominant pathogens found in the European prevalence of infections in intensive care study. Eur. J. Clin. Microbiol. Infect. Dis. 15: 281285. Vuong, C., Kocianova, S., Voyich, J. M., Yao, Y., Fishcer, E. R., DeLeo, F. R., Otto,

M. 2004. A crucial role for exopolysaccharide modification in bacterial biofilm formation, immune evasion, and virulence. J. Biol. Chem., 279: 5488154886. Wang, X., Preston, J. F. I., Romeo, T. 2004. The pgaABCD locus of Escherichia coli promotes the synthesis of a polysaccharide adhesin required for biofilm formation. J. Bacteriol., 186: 2724-2734.

\section{How to cite this article:}

Kondal Rao Ravilla, Amar C. Sajjan and Sachin Gurnule. 2018. Biofilm Detection and Clinical Significance of Staphylococcus epidermidis Isolates in a Tertiary Care Hospital, Karimnagar, India. Int.J.Curr.Microbiol.App.Sci. 7(12): 2157-2163.

doi: https://doi.org/10.20546/ijcmas.2018.712.244 